\title{
EVIDENCE-BASED DESIGN OF A TOURIST BROCHURE BASED ON WORSHIPING BEHAVIOR IN LONGSHAN TEMPLE, TAIWAN
}

\author{
MENG-CONG ZHENG \& TZU-CHUN TSAI \\ Department of Industrial Design, National Taipei University of Technology, Taiwan
}

\begin{abstract}
The number of visitors to Taiwan is increasing, but most of them experience it with at just a passing glance and shallow experience. The purpose of this study is to redesign the tourist brochure to provide practical information for visitors. This study was implemented based on the Longshan Temple. The first stage investigated 50 tourists' behavior in the Temple. We found the utilization rate of worshiping information was only $20 \%$. Search time was $15 \%$ of the total visiting time; $38 \%$ of the visitors were confused because they were looking for where the worshiping objects were. Most visitors left after taking photos, unable to understand and experience the culture of the temple. In the second stage, based on the results of the visiting tasks and questionnaire, we found the "Visit ceremony", "Visit order", "guide map", and "temple history story" of the new tourist brochure should be redesigned. In the third stage, the verification results show that the correct rate of the new brochure for worshiping Longshan Temple is higher than $80 \%$. The information about the order of visit is critical for worshiping. The new tourist brochure design effectively enhances the visitor experience.
\end{abstract}

Keywords: evidence-based design, tourist brochure, worshiping behavior, Longshan Temple.

\section{INTRODUCTION}

Tourism is an economic activity with relatively small impact, it can promote social and cultural progress and improve local residents' welfare [1]. Urban tourism has received little attention among studies of urban planning and sustainable tourism [2], which mostly emphasizes environmental problems [3]-[5]. Increasingly, case studies have discussed the impact of tourism on specific cities by identifying the factors affecting residents' satisfaction [6] as well as the effects of protest movements and the media [7], [8]. The tourism industry should have the potential to promote urban development, encouraging cultural exchange, and thus creating a civilized, vibrant, and safe urban environment [9]-[11].

Religious tourism is a multifaceted tourism category, and many countries regard religious culture as a key tourism asset. Taiwan has a diverse and unique religious culture. Statistics show that the total number of temples in Taiwan has reached 13,305; the popularity of religion in Taiwan is summarized in the expression "a small temple within five steps and a large temple within ten steps". At various well-known religious sites in Taiwan, tourist numbers even exceed those at natural scenic areas and amusement parks [12]. Religious tourism locations also encourage the development of the peripheral economy, including transportation, accommodation, catering, and souvenirs [13]. Shinde [14] refers to Rinschede [15] and Shinde [16]: "Religious tourism refers to contemporary patterns of visitation to places of religious importance or pilgrimage sites where visitors aim to fulfill religious needs and recreational needs". Ebadi [17] found that people visit the same site with very different motivations. In the same place, they are religious pilgrimage for some while encompassing pilgrimage or tourism for others. The value of religious tourism has been found in recent years. Jauhari and Sanjeev [18] propose that religious tourism is seen as travel with a purpose and resistant to the current economic slowdown. Melian et al. [19] propose that both religious and secular tourists gave importance to different factors inaccessibility. On the other hand, 
there is a diversity of religious tourism around the world. Sharma and Sharma [20] mention the fairs and festivals at Pithoragarh in India, have the expression of religious values. The Yanshuei Fireworks Festival in Taiwan started as a local religious ritual but is now a tourist attraction as well [21]. Clarke [22] refers to the Santa Claus Village theme park in Finland, which uses Christmas as a tourist "pull". Porananond [23] similarly asserts in the context of sand pagodas in Thailand: "traditional religious practices have been transformed into commercialized tourist attractions" for people who may not be religious tourists. Service provision and amenities are important even for them [24], [25]. Therefore, how to improve the attraction of religious tourism locations is an important topic for the development of religious tourism.

Holbrook and Hirschman [26] believed that a tourist product covers the physical object itself, the service, and the consumer experience, through which tourists can form long-lasting memories. They believed that experience stems from tourists' pursuit of adventure and happiness. Pine et al. [27] argued that experience should be tourist-centered and that services and products should be used to create memorable activities. During the process of consumption, tourists not only invest money but also time and effort; thus, tourists also hope to obtain their desired outcome [28], which is contained within the consumer experience. Tourists care about the depth and breadth of the experience rather than the size or quantity of the product [29]. Increasingly, cities are being shaped into creative spaces to encourage the sharing of experiences between residents and tourists [30]. This includes the application of concepts such as sustainable experience design, location making, and hospitality.

Longshan Temple in Wanhua District, the National Palace Museum, and the Chiang KaiShek Memorial Hall are three major tourist destinations for foreign tourists visiting Taipei. Longshan Temple was selected for the present study. Constructed in 1738, it is a temple that represents the integration of Confucianism, Buddhism, and Taoism in Taiwan, and it has special rules of worshiping that differ from those of other temples. Longshan Temple currently has three types of wayfinding information for visitors: a navigation map, direction indicators, and navigation brochures. However, the existing information does not enable tourists to complete their visit smoothly and deprives them of an in-depth experience and understanding of the unique worship culture of Longshan Temple and Taiwan's temple culture. Among the three types of wayfinding information at Longshan Temple, navigation brochures are the most flexible and can carry more information, which is required given the complexity of the temple's cultural rules. Zhou [31] discovered that tourists often use navigation brochures to plan travel itineraries and visit tourist attractions, and that half of tourists refer to tourist brochures during their travel. The low cost, easy access, and portability of navigation brochures makes them an indispensable advertising media for marketing and tourism. Navigation brochures are also the most common tool for tourist sites to convey information to tourists. The main purpose of navigation brochures is to convert potential tourists into actual tourists, who then visit local attractions, through tourism marketing [32][34]. The purpose of this study was to design a navigation brochure to enable tourists to have a deep experience of Taiwan's temple culture at Longshan Temple, thereby reducing excessive superficial sightseeing. First, the characteristics of tourists' wayfinding behaviors at Longshan Temple were observed, and the relevant mobility problems were formulated through simulated worship experiments. Second, tourists' expectations regarding navigation brochure information were studied. Finally, the navigation brochure was proposed for verification, thereby providing a reference for future designs. 


\section{METHOD}

Longshan Temple in Wanhua District was the observation and research site. In this study, Longshan Temple was divided into the front pavilion, front hall, center hall, main hall, rear hall, and outdoor area. Area A - part of the front pavilion - is the plaza in front of Longshan Temple and the location of celebrations during festivals. Area B - also part of the front pavilion - is the main entrance where the incense and candle shop, service center, tourist service center, and souvenir shop are located. In this area, visitors can light their incense and find the fortune stick holders, fortune stick closets, and divination blocks. Area $\mathrm{C}$ consists of the center hall, which is a roofless area where the incense furnace of the Guanyin is placed. Area D is the front hall, which includes the cloister, Yuantongbao Hall, the donation site, and the information for fortune stick interpretation. Area $\mathrm{E}$ is the rear hall, where most of the shrines are located, including the Huatuo Hall, Wenchang Dijun Hall, Mazu Hall, Guansheng Dijun Hall, and Yue Lao Hall. Area F is the outdoor area, which includes the flower beds, bathrooms, and barrier-free ramps (Fig. 1). Behavioral observation, task Analysis and questionnaire for the interview were implemented in this study. Behavioral observation is referred to as sequential action marking; this method is a type of continuous observation-recording, and its objective is to record the relationship between time and actions. Task Analysis aims to observe participants to understand the process in action, to learn more about the user how to perform a task, and achieve the user expectations [35]. The investigation was divided into three stages:

Stage I: A total of 50 tourists who speak foreign languages were observed with behavioral mapping, including where they visited, wayfinding, and sightseeing behaviors at Longshan Temple in one day. Foreign tourists were identified at the entrance of Longshan Temple randomly based on the language, then recorded the entire process by GoPro until the tourist left the temple. These behaviors were analyzed to assess the problems that tourists encounter at the temple.

Stage II: Worship task experiment. A total of 30 individuals between $20-40$ years old who never visited Longshan Temple were assigned a worship task that simulated the sightseeing situation based on the complete worship process, including holding incense, lighting candles, casting divination blocks, and drawing fortune sticks. Then asked to complete a questionnaire and answer interview questions to understand the information that they referred to when performing the tasks and where they encountered difficulties to determine whether the wayfinding information at Longshan Temple was useful to worshipers. The whole experiments of stage II were implemented in two weeks.

Stage III: Design proposal and verification. The findings from stage I and II were summarized into conditions that served as the basis for brochure design. For the verification stage, eight men and eight women between 20-40 years old who never visited Longshan Temple were recruited. All participants were requested to complete the worship process based on the instructions in the navigation brochure. Upon completion, they were asked to complete a questionnaire, draw a cognitive map, and answer interview questions to evaluate their experience. Stage III was implemented in one week. 

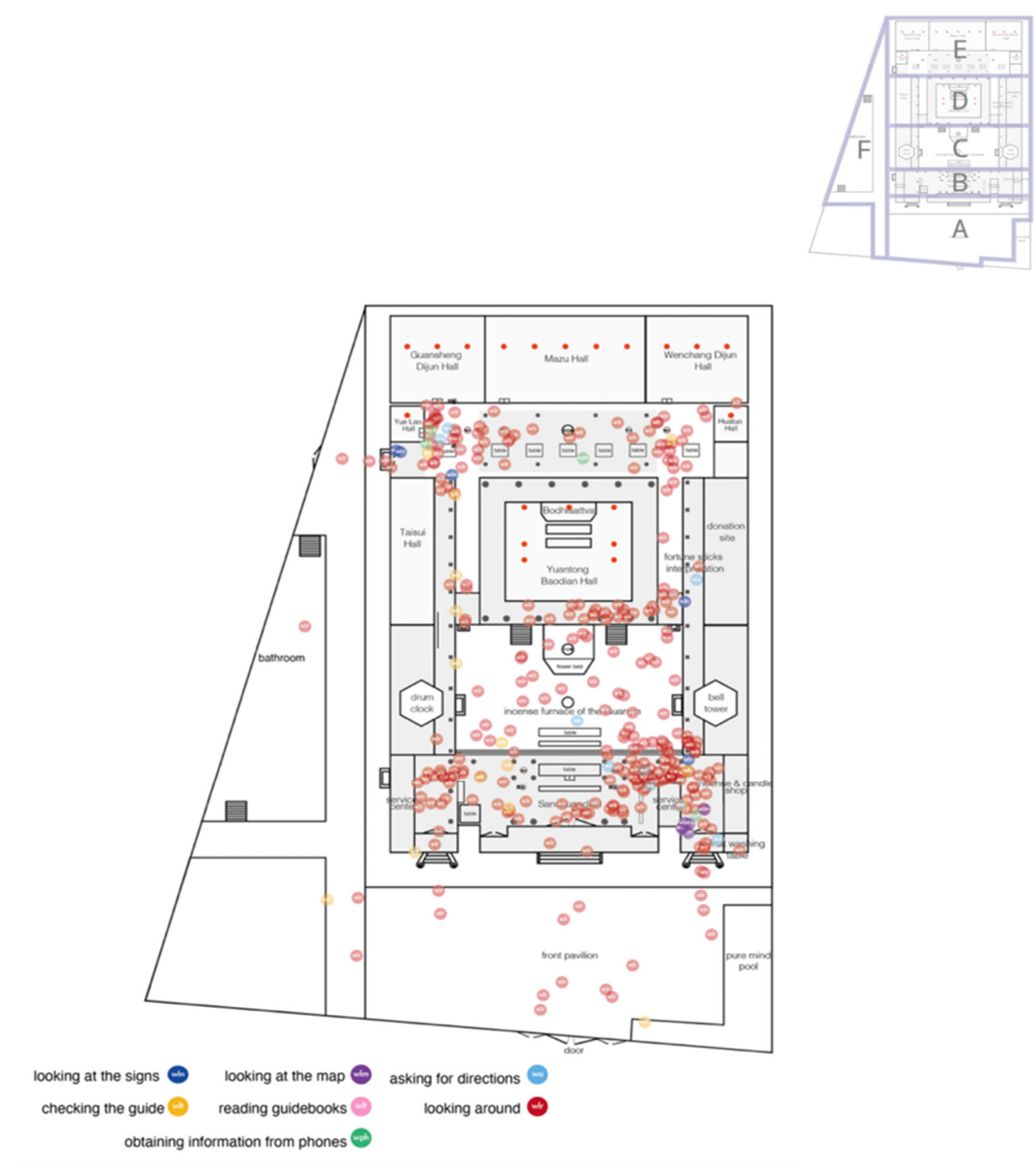

Figure 1: Five areas of Longshan Temple and behavioural mapping from non-participant observation.

\section{RESULTS}

\subsection{Stage I: Non-participant observation on tourist behaviors}

During the first stage of observation, the 50 foreign tourists' average length of stay at Longshan Temple was 24 minutes 18 seconds: among the six areas, the longest stay was in the front hall of Area B (8 minutes 12.2 seconds), followed by Areas E, A, C, D, and F. The traffic flow in Area A was chaotic because tourists would walk around to take photographs. 
In Area B, tourists moved back and forth several times to locate the place to obtain incense, resulting in an overlapped traffic flow. The flow in Area D was more consistent due to the narrow passage. Most tourists in Area E walked counterclockwise from Huatuo Hall to Yue Lao Hall and then walked around Yue Lao Hall to receive their red thread, resulting in a relatively disordered flow. In addition, observation revealed that the navigation maps at Longshan Temple were placed on both sides of the wall at the Longmen entrance of Area B (front hall). The maps on the right side of the entrance are Chinese maps and were obscured by an automated teller machine. The maps on the left side of the entrance had a usage rate of only $8 \%$. Guidance signs were installed on the pillars at the entrance to Area C from Area B and the entrance to Area E from Area D, as well as on the door to Area F from Area E; however, because of their installation height, they were easily obstructed by the crowd, resulting in a $10 \%$ usage rate. The navigation brochures, which were placed on the service counter to the left of Area B (front hall), had a usage rate of only $16 \%$. Among the six areas, the average times for looking around, asking for directions, looking at the map, and looking at the signs were highest in Area B. When entering Area B, tourist often looked around to understand the environment. If they missed the incense and candle shop, they searched for the placed to acquire incense and thus asked for directions. The map was located in Area B (front hall), and tourists would look at the map as soon as they discovered it when entering from the Longmen entrance.

Checking the guide and obtaining information from mobile phones mostly occurred when tourists were confirming the procedures for drawing fortune sticks and casting divination blocks. In Area $\mathrm{C}$ - a roofless, well-lit transition area - the most common activity was looking around. Reading guidebooks was the most common behavior in Area F (Figs 1 and 2).

The average times of worshiping and nonworshiping visitors were 26 minutes and 16 seconds and 17 minutes and 21 seconds, respectively. Observations revealed that $27.3 \%$ of visitors did not worship because they could not locate their incense in Area B. One nonworshiping visitor purchased souvenirs, whereas 14 worshiping visitors purchased souvenirs. Because most of the shrines in Longshan Temple are located in Area E, this area had the second highest average sightseeing time of all areas (for both worshiping and nonworshiping visitors). Nonworshiping visitors left the temple area immediately after exiting the temple (Fig. 3). None of the 39 foreign tourists who acquired incense and worshiped the deities were able to perform a complete worship, with most visitors making mistakes in the order of halls to worshiping at. The maps and navigation brochures at Longshan Temple only indicated the order of the incense burners and did not specified the order of halls, traffic flow, or worshiping process. Furthermore, tourists hesitated at the turning points of routes and in well-lit transition areas. Because the location of the incense and candle shop was unclear, tourists would return to the area after missing the shop, resulting in a disordered traffic flow. Only approximately $20 \%$ of the tourists used the wayfinding guidance system in the temple. The average staying time of tourists at Longshan Temple was 24 minutes and 18 seconds, and wayfinding accounted for nearly $15 \%$ of this time. Of the $78 \%$ of foreign tourists who worshiped the deities, none completed the correct worship process. Tourists who worshiped the deities stayed longer than the nonworshipers. However, $27.3 \%$ of worshiping visitors forewent the worship process because they failed to locate the incense shop in Area B (front hall). Nonworshipers purchased fewer souvenirs than worshipers. These results demonstrated the numerous problems with the worship information in Longshan Temple. Of the three guiding tools in the temple (i.e., navigation maps, navigation brochures, and guidance signs), only navigation maps and brochures indicated the order of incense burners; however, the lack of other worship information resulted in a usage rate of less than $20 \%$. 


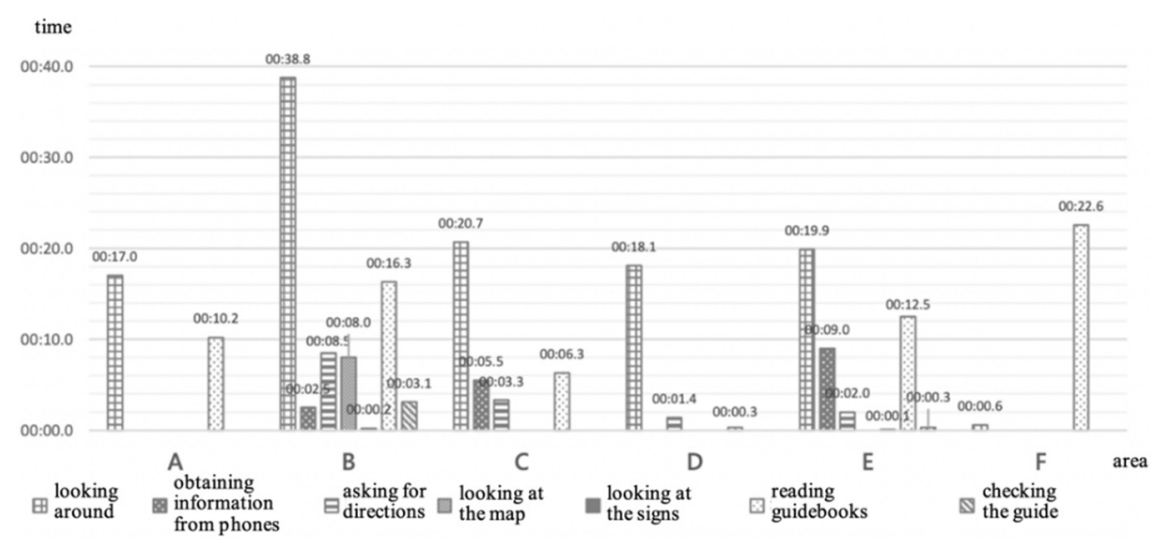

Figure 2: The average times of information searching behavior in each Area.

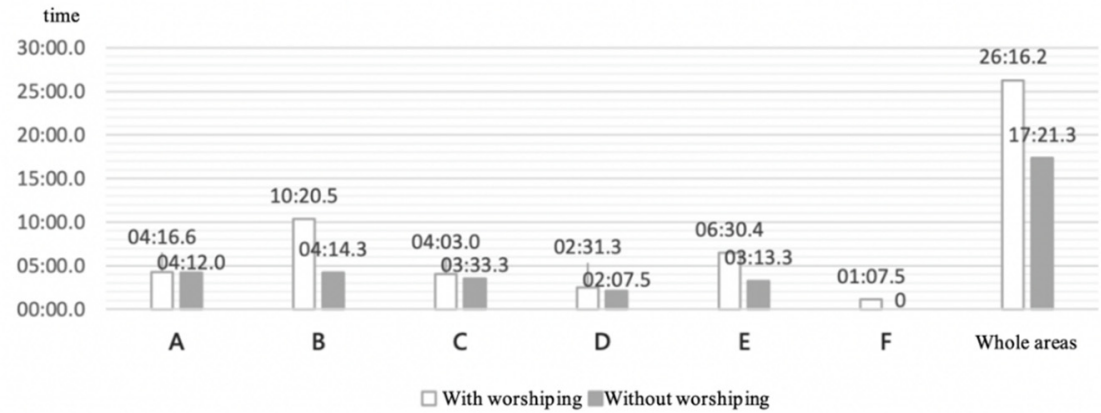

Figure 3: The average times of worshiping in each Area.

\subsection{Stage II: Worship task experiment}

The findings of the worship simulation experiment were similar to those of the observation in the first stage. Because the wayfinding information for worshiping in Longshan Temple was vague, the participants mostly asked others to acquire information about the worshiping tasks such as lighting candles, casting divination blocks, and drawing fortune sticks. The participants exhibited the most disordered traffic flow at Area B (front hall), and they repeatedly walked between the candle and incense shop and the incense burner to confirm the object positions. Most participants stated that the wayfinding information in the temple was not helpful for their tasks, and they obtained useful information by asking volunteers or other worshipers. They all encountered difficulties in "location" and "process". When asked about the importance of worship information, the participants ranked "the significance and process of worship with incense" as the most important, followed by "the significance and process of drawing fortune sticks", "worship order", "the significance and process of casting divination blocks", "introduction of deities", and "the significance and process of lighting candles". The participants ranked "historical stories" and "temple art" as the least important. 


\subsection{Stage III: Design proposals and verification}

Most navigation brochures provided in temples have a folded area of less than $10.5 \times 21.0$ $\mathrm{cm}^{2}$ (Cheng, 2009); their dimensions are mostly in the range 10.0-10.5 $\times 18.8-21.5 \mathrm{~cm}^{2}$, which is convenient for tourists to collect and carry. However, these brochures typically do not contain introductions to the worship process at the temple and mostly focus on historical stories, temple art, and deities. The Longshan Temple navigation brochure designed in this study was assigned a dimension of $39 \times 21 \mathrm{~cm}^{2}$, with a default paper size of $8 \mathrm{~K}(39 \times 27$ $\mathrm{cm}^{2}$ ). The brochure was a five-fold map, where the width of one fold was $6.5 \mathrm{~cm}$, and it complied with the design conditions that the brochure should be smaller than $10 \times 21 \mathrm{~cm}^{2}$. The outer wall color of Longshan Temple (light khaki, C: 1, M: 7, Y: 17, K: 0) served as the main background color of the brochure. The contents of the brochure were prepared on the basis of the questionnaire and interview results; they comprised "worship ceremony: light candles, worship with incense, cast divination blocks, request a red thread, and draw fortune sticks", "guidance on worship order", "floor plan", "facility configuration", "deities introduction", "temple art", and "historical stories". The preliminary layout for the brochure was based on a single fold $\left(6.5 \times 21 \mathrm{~cm}^{2}\right)$ as the unit. The navigation map was a three-dimensional map of Longshan Temple illustrated using 3D drawing software. Deity images were inserted into the map according to their shrine locations, and short texts were included to introduce them. Border design elements same as the front and back covers were used to distinguish the deity images from the navigation map, and arrows were incorporated into the border patterns to indicate the locations of the shrines. Finally, images of the worship ceremony were added with numbers indicating the order of worship for tourists to refer to (Fig. 4).

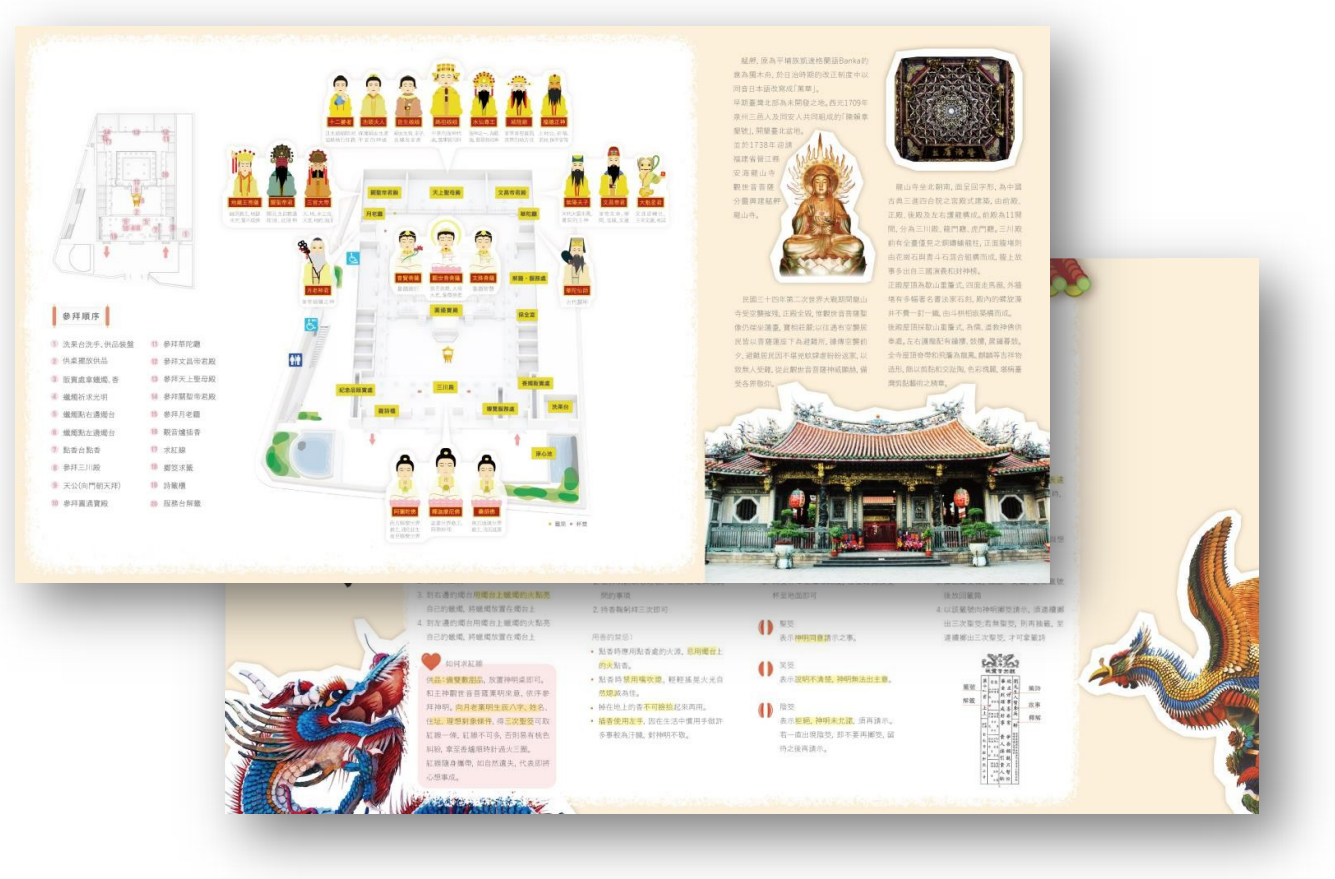

Figure 4: New navigation brochure of Longshan Temple. 
The third stage of the experiment revealed that all 16 participants had performed worship actions such as lighting candles, worshiping with incense, casting divination blocks, and drawing fortune sticks. The task with the highest accuracy rate was casting divination blocks and requesting a red thread (100\%), followed by worshiping with incense $(93.75 \%)$ and drawing fortune sticks $(93.75 \%)$. The correct worship order was "light candles $\rightarrow$ worship with incense $\rightarrow$ cast divination blocks $\rightarrow$ draw fortune sticks", and 15 of the 16 participants performed with the worship in the correct order, with an accuracy rate of $93.75 \%$. The overall traffic flow and moving sequence were more consistent than in the previous case (Fig. 5).

Analysis of worship actions when using the new brochure revealed the following findings:

- Lighting candles: The participants referred to the order of worship when lighting candles to understand their significance. Participants who referred to the information on worship ceremony and worship order accounted for $81.25 \%$. These participants exhibited behaviors of repeatedly checking the content of the brochure.

- Worshiping with incense: Participants read the folder when walking during their worshiping process, which affected the traffic flow of other worshipers and required improvement. The participants referred to the brochure to confirm their next action when performing a worship sequence. All participants referred to the worship order.

- Casting divination blocks: Before casting the divination blocks, the participants read the worship order to identify the correct location and understand how to cast the blocks. Most participants read the brochure at fixed location. A total of 14 participants referred to the information on the worship ceremony, and nine of them referred to the worship order.

- Requesting a red thread: Most participants did not notice this information; thus, the brochure layout required further adjustment.

- Requesting fortune sticks: Fortune stick holders and divination blocks are placed in the same location. The participants knew the location of the holders if they had found the divination blocks; thus, they only read the worship order after obtaining their fortune stick number.
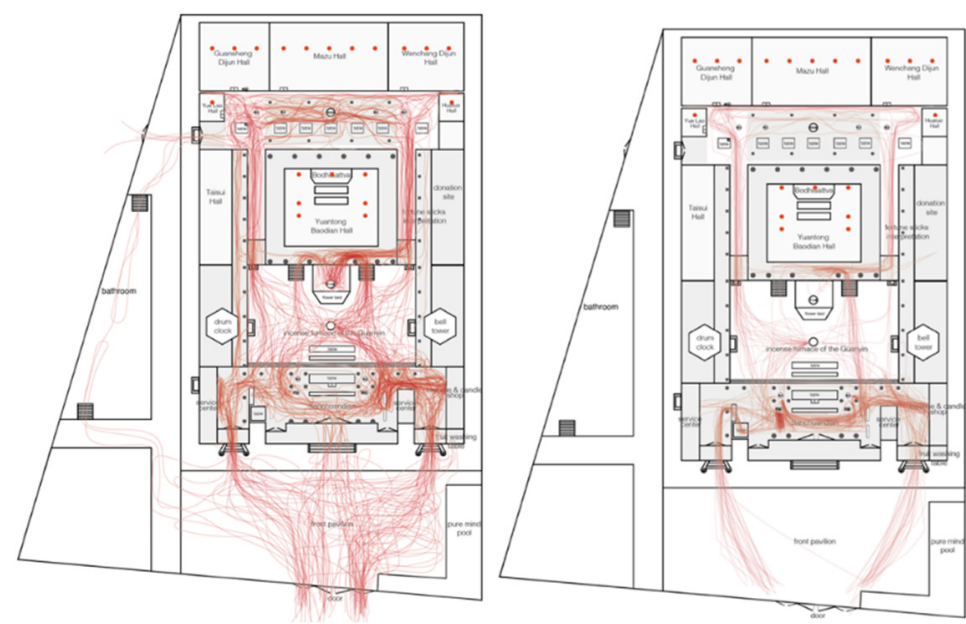

Figure 5: Traffic flow of Longshan Temple with and without new brochure. 


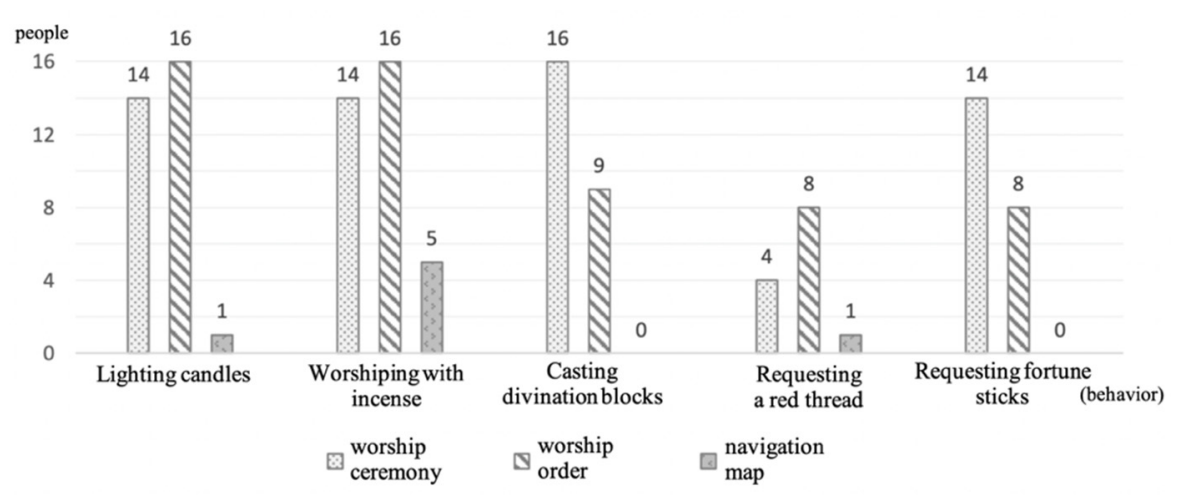

Figure 6: Utility rate of brochure information in each worshiping behavior.

All participants referred to the worship order in the brochure when lighting the candles and worshiping with incense. However, the number of participants who referred to the worship order was lower when casting the divination blocks and requesting fortune sticks; for these tasks, most participants referred to the information on the worship ceremony. This indicated that lighting candles and worshiping with incense required worshipers to move, thus increasing the importance of the floor plan and worship order. Because casting divination blocks and requesting fortune sticks were performed in the same location, the participants referred to the information on the worship ceremony after identifying the relevant location. Few participants used the navigation map; the participants stated that because the worship order had been marked on the floor plan, they were able to understand the spatial configuration of Longshan Temple. In general, the information that was referred to by most participants when lighting candles was worship order and worship ceremony (13 participants). The participants spent the longest average time reading the information on the worship ceremony. When the participants were lighting candles, the highest result for participants looking around (wlr) was observed in Area B (front hall). Participants primarily referred to the information on worship order and the worship ceremony when worshiping with incense, and they spent the longest average time on reading the worship order. When the participants were casting divination blocks, the information most often referred to was also worship order and worship ceremony; however, they spent the longest time in reading about the worship ceremony. Finally, the nine participants who requested a red thread referred to the information on worship order. The aforementioned findings demonstrate that the information within the temple should correspond to the diverse behaviors and needs of visitors (Fig. 6).

\section{DISCUSSION}

The observations revealed that the tourists exhibited disordered traffic flow during worshiping. During the second stage of the experiment (worship simulation experiment), 18 of the 30 participants (60\%) walked back and forth; however, this decreased to $31.25 \%$ during the third stage (verification experiment). During the second stage, the average time each participant spent looking around when lighting the candles was 14.1 seconds, whereas this decreased to 4.4 seconds during the third stage. 
Moreover, during the second stage, the average time each participant spent looking around when worshiping with incense was 11.6 seconds, whereas this decreased to 2.7 seconds during the third stage. The observations revealed that the participants spent more time looking around for the incense before implementing the new navigation brochure. After learning from the brochure, they were more certain that the correct worship process was lighting a candle followed by worshiping with incense. During the second stage, 25 participants performed the action of worshiping with incense first; however, only one participant did so during the third stage (Fig. 7).

During the second stage, the average time each participant spent looking around when casting divination blocks was 2.1 seconds, whereas this decreased to 1.2 seconds during the third stage. Although this difference was small, the participants were able to locate the fortune stick holder in the temple. Therefore, marking the location of the holder on the floor plan of the navigation brochure only yielded limited improvement. Similarly, during the second stage, the average time each participant spent looking around when requesting fortune sticks was 3.5 seconds, whereas this decreased to 1.7 seconds during the third stage. In both stages, the participants were able to find the location for requesting the fortune sticks.

The accuracy rates for lighting candles, worshiping with incense, casting divination blocks, requesting fortune sticks, and the overall worship process in the verification experiment showed huge improvements relative to the worship task experiment. Moreover, the accuracy rates of worship actions in the verification experiment were all higher than $80 \%$. Reisinger and Mavondo [36] noted that tourists may feel anxious if they have trouble finding their way during sightseeing and may be less willing to return in the future. The navigation brochure designed in this study was inferred to effectively guide worship action (Fig. 8).

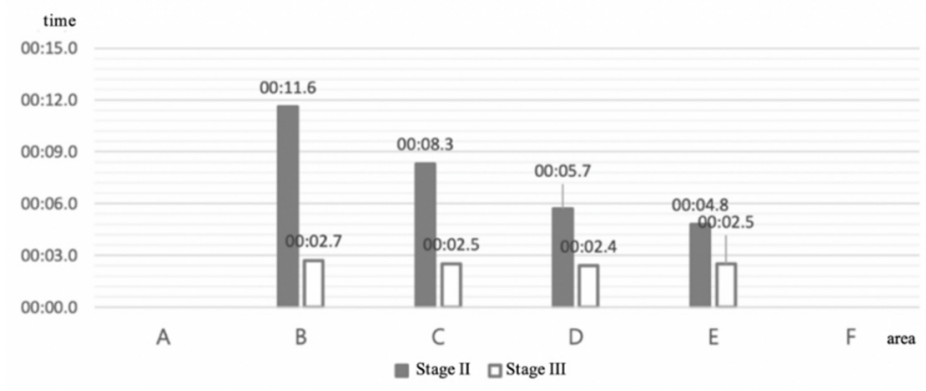

Figure 7: Average time each participant spent looking around when worshiping.

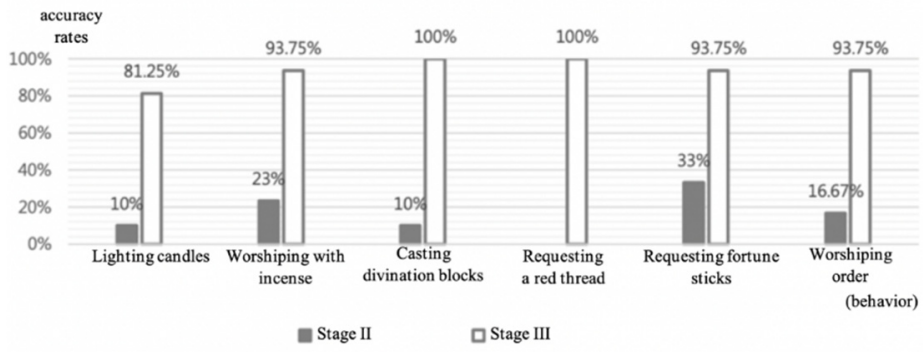

Figure 8: Accuracy rates of each worshiping behavior. 


\section{CONCLUSION}

Observations in this study revealed that foreign tourists who tried to worship at the temple lacked understanding of the worship process because of the numerous unclear signs. They repeatedly walked back and forth, resulting in disordered traffic flow. In addition, $27.3 \%$ of the tourists did not worship because they could not locate the incense shop. This study revealed that foreign tourists' average length of stay at Longshan Temple was approximately 24 minutes and 18 seconds; $15 \%$ of this time was spent on wayfinding. In particular, wayfinding time in the front hall was higher than that in other areas, indicating that the information within the temple remains incomplete. Visitors often asked others for information on worshiping in Longshan Temple, which increased the burden on volunteers. Longshan Temple has three types of guiding objects: a navigation map, navigation brochures, and guidance signs, with usage rates of less than $20 \%$. Surveys conducted in this study showed that tourists wanted information about the worship ceremony when visiting the temple. In the hand-drawn map survey, respondents often drew the objects mentioned in the worship order, clearly indicating that location information affected their spatial perception. Therefore, the spaces that visitors use should be considered when designing the location-related information. Circuitous tours enable tourists to know better particular areas and travel ranges [37]. It can be defined according to the moving distances, moving ranges, and traversed areas of tourists [38]. We must acknowledge the visibility of environmental features can encourage tourist familiarization with a place [39]. Therefore, site maps must both support circuitous movements and provide enough information to help tourists plan. Providing new tour information is an important factor in promoting the frequency of circuitous tour movements. Information intended for circuitous tour movements provides richness and freedom of choice, though it might not indicate the shortest travelling route. Adding directional information can enable tourists to move more smoothly during their visit. The navigation brochure provided at Longshan Temple only introduced temple-related historical stories and art; however, this study revealed that historical stories and temple art are of low importance to visitors. Thus, designers must consider whether to present the relevant information in brochures and maps or incorporate it in guidance signs. To provide appropriate information, designers must also evaluate the different behaviors of visitors to Longshan Temple, including whether they are moving continuously or worshiping at fixed locations. Experience is one of the most crucial values in religious tourism, and it enables visitors of different religions to understand the meaning and central ideas of the religious site. Information on the worship process can be provided during worship ceremonies to give visitors a profound impression when experiencing the religious actions. Participation in worshiping increased visitors' willingness to purchase souvenirs in the present study, thereby increasing profit for the tourist attraction. This study demonstrated that an improved navigation design encourages a satisfactory tourism experience. The research process and method can serve as a reference for future studies on sustainable tourism.

\section{REFERENCES}

[1] Hall, C.M., Tourism urbanization and global environmental change. Tourism and Global Environmental Change: Ecological, Economic, Social and Political Interrelationships, eds S. Gossling \& C.M. Hall, London: Routledge, pp. 142-156, 2006.

[2] Ashworth, G. \& Page, S.J., Urban tourism research: Recent progress and current paradoxes. Tourism Management, 32(1), pp. 1-15, 2011.

[3] Bramwell, B., Theoretical activity in sustainable tourism research. Annals of Tourism Research, 54, pp. 204-218, 2015. 
[4] Buckley, R., Sustainable tourism: Research and reality. Annals of Tourism Research, 39(2), pp. 528-546, 2012.

[5] Ruhanen, L., Weiler, B., Moyle, B.D. \& McLennan, C.J., Trends and patterns in sustainable tourism research: A 25-year bibliometric analysis. Journal of Sustainable Tourism, 23(4), pp. 517-535, 2015. https://doi.org/10.1080/09669582.2014.978790.

[6] Kuščer, K. \& Mihalič, T., Residents' attitudes towards overtourism from the perspective of tourism impacts and cooperation - The case of Ljubljana. Sustainability, 11(6), 1823, 2019. https://doi.org/10.3390/su11061823.

[7] Hughes, N., Tourists go home': Anti-tourism industry protest in Barcelona. Social Movement Studies, 17(4), pp. 471-477, 2018.

[8] Milano, C., Overtourism, social unrest and tourismphobia. A controversial debate. PASOS: Revista de Turismo y Patrimonio Cultural, 16(3), pp. 551-564, 2018.

[9] Fainstein, S.S., The Just City, Cornell University Press: Ithaca, 2010.

[10] Sennett, R., The Fall of Public Man, W.W. Norton \& Company: London, 1992.

[11] Sennett, R., Together: The Rituals, Pleasures and Politics of Cooperation, Yale University Press: New Haven, 2013.

[12] Dahe, L., Tourism and Cultural Festivals-Taiwan's current tourism development focus, Research on APEC Issues for Tourism and Cultural Festivals, APEC Research Center: Taipei, pp. 14-21, 2011.

[13] Jian-Ming, C., Tourism attractiveness of religious sites in Taipei: A case study of Lungshan Temple and Hsingtien Temple. Master's thesis, National Taiwan University. https://hdl.handle.net/11296/287bm7, 2005.

[14] Shinde, K.A., Religious tourism and religious tolerance: Insights from pilgrimage sites in India. Tourism Review, 70(3), pp. 179-196, 2015.

[15] Rinschede, G., Forms of religious tourism. Annals of Tourism Research, 19(1), pp. 5167, 1992.

[16] Shinde, K.A., Visiting sacred sites in India: Religious tourism or pilgrimage? Religious Tourism and Pilgrimage Festivals Management: An International Perspective, eds R. Raj \& N.D. Morpeth, CABI: Wallingford, pp. 186-199, 2007.

[17] Ebadi, M., Typologies of the visitors at Khaled Nabi Shrine, Iran: tourists or Pilgrims? International Journal of Culture, Tourism and Hospitality Research, 8(3), pp. 310321, 2014.

[18] Jauhari, V. \& Sanjeev, G.M., Managing customer experience for spiritual and cultural tourism: an overview. Worldwide Hospitality and Tourism Themes, 2(5), pp. 467-476, 2010.

[19] Melian, A.G., Prats, L. \& Coromina, L., The perceived value of accessibility in religious sites - do disabled and non-disabled travellers behave differently? Tourism Review, 71(2), pp. 105-117, 2016.

[20] Sharma, S. \& Sharma, S., Understanding Pithoragarh's cultural jewels: its fairs and festivals. Worldwide Hospitality and Tourism Themes, 7(4), pp. 331-346, 2015.

[21] Cheng, T.-M., Chang, S. \& Dai, Z., The mediating effect of situation involvement of novelty seeking and satisfaction for Yanshuei fireworks festival in Taiwan. International Journal of Culture, Tourism and Hospitality Research, 9(2), pp. 154167, 2015.

[22] Clarke, P., Christmas gift giving involvement. Journal of Consumer Marketing, 23(5), pp. 283-291, 2006.

[23] Porananond, P., Tourism and the transformation of ritual practice with sand Pagodas in Chiang Mai, Northern Thailand. Tourism Review, 70(3), pp. 165-178, 2015. 
[24] Durgamohan, M., Cultural and economic significance of Hampi festival. Worldwide Hospitality and Tourism Themes, 7(4), pp. 377-392, 2015.

[25] Jauhari, V., Hospitality, tourism and economic growth in India. Worldwide Hospitality and Tourism Themes, 1(1), pp. 7-11, 2009.

[26] Holbrook, M.B. \& Hirschman, E.C., The experience aspects of consumption Consumer fantasies, feelings, and fun. Journal of Consumer Research, 9(2), pp. 132-140, 1982.

[27] Pine, B.J., Pine, J. \& Gilmore, J.H., The Experience Economy: Work Is Theatre \& Every Business a Stage, Harvard Business Press: Cambridge, MA, 1999.

[28] Mathwick, C., Malhotra, N. \& Rigdon, E., Experiential value: Conceptualization, measurement and application in the catalog and Internet shopping environment. Journal of Retailing, 77(1), pp. 39-56, 2001.

[29] Pei-fen, W., Study on the experience value of Watson's female skin care products. Journal of Hospitality and Home Economics, 5(3), pp. 295-310, 2008.

[30] Russo, A.P. \& Richards, G., Reinventing the Local in Tourism: Producing, Consuming and Negotiating Place, Channel View Publications: Bristol, 2016.

[31] Zhou, Z., Destination marketing: Measuring the effectiveness of brochures. Journal of Travel \& Tourism Marketing, 6(3-4), pp. 143-158, 1997.

[32] Gets, D. \& Sailor, L., Design of destination and attraction-specific Brochures. Journal of Travel and Tourism Marketing, 2(2/3), pp. 111-131, 1993.

[33] Jenkins, O., Photography and travel brochures: The circle of representation. Tourism geographies, 5(3), pp. 305-328, 2003.

[34] Chang, W.-C., Rethinking resource identification and utilization: The reconstruction of indigenous ethnoecological knowledge in Fata'an Wetland, Taiwan. Management of Environmental Quality: An International Journal, 22(2), pp. 187-199, 2011.

[35] Hackos, J.T. \& Redish, J.C., User and Task Analysis for Interface Design, John Wiley \& Sons, 1998.

[36] Reisinger, Y. \& Mavondo, F., Travel anxiety and intentions to travel internationally: Implications of travel risk perception. Journal of Travel Research, 43(3), pp. 212-225, 2005. https://doi.org/10.1177/0047287504272017.

[37] Takashi, S., On the circuit system and urban environmental formation in urban tourism. Vol. 2: On Practical Use of Historical Heritage for Urban Tourism in Himeji, pp. 485-488, 2005.

[38] Kaori, H., On the influence of a city map as a guide for rambling downtown beyond main streets: On the citizen's rambling activity in urban streets and their spatial cognition, pp. 213-214, 2011.

[39] Yuichi, S., "The Visual Information which encourage or Restrain Citizens" Strolling Activities in Urban Space: On the relationship of strolling activities and visual information given by the environment in downtown Kumamoto Part II. Journal of Architecture and Planning, 72(614), pp. 191-197, 2007. 